\title{
Re-emergence of susceptibility to conventionally used drugs among strains of Salmonella Typhi in central west India
}

\author{
Yashwant Kumar, Anshu Sharma, and Kavaratty Raju Mani \\ National Salmonella and Escherichia Centre, Central Research Institute, Kasauli, 173204, Himachal Pradesh, India
}

\begin{abstract}
Introduction: Typhoid fever (enteric fever) is a global health problem causing high morbidity and mortality, especially in endemic areas such as India. The problem is exacerbated as the causative agent, Salmonella enterica subspecies enterica serovar Typhi (S. Typhi), rapidly develops resistance to drugs used in treatment. However, non-responsiveness of $S$. Typhi to quinolones has been reported simultaneously with the re-emergence of susceptibility to chloramphenicol. The present study investigates the re-emergence of sensitivity to conventionally used drugs among strains of $S$. Typhi in the central west part of India.

Methodology: We evaluated 128 S. Typhi isolates received at the National Salmonella and Escherichia Centre for chloramphenicol, ampicillin and trimethoprim susceptibility using standard methods. Minimum inhibitory concentrations were also evaluated.

Results: The proportion of $S$. Typhi isolates showing susceptibility to chloramphenicol, ampicillin, and trimethoprim was $95.3 \%, 94.5 \%$, and $94.5 \%$, respectively. These findings may help the health authorities in reconsidering the addition of these antimicrobial drugs into the treatment regime of typhoid fever and therefore may help combat the problem of increasing resistance to quinolones and cephalosporins.

Conclusion: The changing trends of $S$. Typhi resistance patterns necessitate reconsideration of conventionally used drugs in typhoid fever treatment in India. In the present study, $S$. Typhi strains exhibited increased susceptibility toward chloramphenicol, ampicillin and trimethoprim, therefore suggesting the possibility of their use for treatment of typhoid fever.
\end{abstract}

Key words: re-emergence; susceptibility; Salmonella Typhi

J Infect Dev Ctries 2011; 5(3):227-230.

(Received 21 June 2010 - Accepted 11 November 2010)

Copyright () 2011 Kumar et al. This is an open-access article distributed under the Creative Commons Attribution License, which permits unrestricted use, distribution, and reproduction in any medium, provided the original work is properly cited.

\section{Introduction}

Typhoid fever (enteric fever) is of worldwide concern, especially in developing countries where it is endemic [1]. Antimicrobial chemotherapy against the causative agent $S$. Typhi emerged as an effective strategy to reduce morbidity and mortality due to typhoid fever [2]. Chloramphenicol was considered to be the gold standard of typhoid fever therapy after its introduction in 1948 [3]. However, strains of $S$. Typhi resistant to chloramphenicol, ampicillin and trimethoprim-sulphamethoxazole (TMP-SMZ) became prevalent in some Asian countries during the late 1980s and early 1990s and emerged as a significant therapeutic problem [4]. South-eastern China is believed to be the origin of this multidrug resistant strain of $S$. Typhi [5]. Due to the prevalence of these strains, the fluoroquinolone ciprofloxacin began to be used for the treatment of typhoid fever [6].

Several studies from different parts of India have reported the development of resistance of $S$. Typhi to various antibiotics $[7,8]$. In the central west parts of India, fluoroquinolones and third-generation cephalosporins are the mainstay of treatment for typhoid fever $[9,10]$. Rampant use of ciprofloxacin in the treatment of typhoid fever led to an increase in the minimum inhibitory concentrations (MIC) of ciprofloxacin in strains of $S$. Typhi [11]. Strains of $S$. Typhi showing in-vitro susceptibility to ciprofloxacin were reported to result in treatment failure due to increased levels of MIC [12]. In recent years there have been several reports indicating the re-emergence of susceptibility to drugs used in the past, such as chloramphenicol, ampicillin and trimethoprim [1,9,13-21]. In the present scenario of decreased clinical responsiveness of typhoid fever cases to ciprofloxacin, the reintroduction of historically useful drugs in the treatment regimen of typhoid fever would be of immense therapeutic importance. The aim of the present study was to study the changing antibiogram pattern of $S$. Typhi with respect to re- 
Table 1. Antimicrobial susceptibility to chloramphenicol, ampicillin and trimethoprim

\begin{tabular}{|c|c|c|c|}
\hline & Chloramphenicol & Ampicillin & Trimethoprim \\
\hline $\begin{array}{c}\text { Number of isolates } \\
\text { (number of susceptible } \\
\text { strains/total number tested) }\end{array}$ & $122 / 128$ & $121 / 128$ & $121 / 128$ \\
\hline MIC range (mg/L) & $0.93-7.5$ & $0.31-1.25$ & $0.03-0.31$ \\
\hline \multicolumn{2}{|c|}{ Resistant isolates } \\
\hline $\begin{array}{c}\text { Number of isolates } \\
\text { (number of resistant }\end{array}$ & Chloramphenicol & Ampicillin & Trimethoprim \\
\hline strains/total number tested) & $6 / 128$ & $7 / 128$ & $7 / 128$ \\
\hline MIC range (mg/L) & $32-64$ & $32-512$ & $16-32$ \\
\hline
\end{tabular}

emergence of susceptibility to conventionally used antimicrobials.

\section{Methodology}

The National Salmonella and Escherichia Centre (NSEC), Central Research Institute, Kasauli, India, has provided a service to the nation for the past five decades, and is a national reference laboratory formerly under the control of the World Health Organization. During the year 2008-2009, 128 isolates of $S$. Typhi were received by the NSEC from 14 hospitals within Maharashtra, and these constituted the material for this study. Maharashtra is the third largest state in India situated in the central west part of the country. This state is India's leading industrial state contributing $15 \%$ of the national industrial output and over $40 \%$ of India's national revenue. The records of all the isolates were retrieved from laboratory records of the department.

All media, antibiotics and biochemicals were obtained from Hi Media Lab. Pvt. Ltd., Mumbai, India. All isolates were identified as $S$. Typhi by conventional biochemical tests [22] and confirmed by serotyping [23] using standard Salmonella agglutinating sera (Seiken Laboratories, Tokyo, Japan). Antibiotic susceptibility patterns of the isolates were determined by the Kirby-Bauer disk diffusion method according to Clinical and Laboratory Standards Institute (CLSI) guidelines and interpretative criteria [24]. Antibiotic disks were used as follows: chloramphenicol $(30 \mu \mathrm{g})$, ampicillin (10 $\mu \mathrm{g})$ and trimethoprim $(5 \mu \mathrm{g})$. Escherichia coli strain ATCC 25922 was used as control. The inocula were prepared by picking three to five well-isolated colonies of the same morphological type into broth and adjusting to obtain a turbidity optically comparable to that of the 0.5 McFarland standard. MIC were determined by agar dilution test [25] using purified antibiotic powders.

\section{Results}

Of the 128 isolates of $S$. Typhi received at the NSEC, $122(95.3 \%)$ were found to be susceptible to chloramphenicol (MIC $0.93-7.5 \mathrm{mg} / \mathrm{L}$ ), and 121 strains $(94.5 \%)$ were susceptible to both ampicillin (MIC $0.31-1.25 \mathrm{mg} / \mathrm{L}$ ) and trimethoprim (MIC 0.03 $-0.31 \mathrm{mg} / \mathrm{L})($ Table 1$)$. MIC ranges were found to be $32-64 \mathrm{mg} / \mathrm{L}, 32-512 \mathrm{mg} / \mathrm{L}$, and $16-32 \mathrm{mg} / \mathrm{L}$, respectively, for chloramphenicol, ampicillin, and trimethoprim in resistant isolates (Table 1).

\section{Discussion}

In the present study, re-emergence of susceptibility to historically used drugs within strains of $S$. Typhi was observed in higher proportions than those reported from different parts of the country [1,16,17-19], with the exception of one study from northern India which reported $96 \%$ sensitivity to chloramphenicol [26]. The results of the present study are in concordance with other studies from the central west part of the country, which also report sensitivity to chloramphenicol, ampicillin and trimethoprim $[9,14,27,3]$, except one which reported $100 \%$ resistance to these drugs [28].

The re-emergence of susceptibility to these drugs may be a result of the emergence of de novo susceptible strains [17] or the loss of high molecular weight self-transmissible plasmids [29]. However, resistance may again develop if multiple drug resistant (MDR) strains are able to transfer their Rplasmids, encoding resistance determinants, to the strains sensitive to these drugs [30]. 
Antimicrobial drugs used for the treatment of typhoid fever are increasingly being used in the treatment of other diseases, leading to problems with antibiotic resistance due to acquisition by $S$. Typhi of resistance-encoding plasmids from other infectious bacteria [31]. Several reports have been published highlighting increased MIC of ciprofloxacin in $S$. Typhi in different parts of the world, including India, therefore resulting in treatment failures [32,33]. In some cases, higher values of ciprofloxacin MIC have been associated with resistance to another quinolone in nalidixic acid resistant $S$. Typhi (NARST) [34]; a high proportion of these strains have been reported from the central west part of India [35]. In the present scenario of fluoroquinolone resistance and the increasing number of reports on the re-emergence of susceptibility to old drugs in the central west part of India, the findings presented here may be of immense importance to aid health authorities to rationalize the policy of empirical treatment of typhoid fever. Furthermore, the return to the use of these drugs includes advantages such as their availability in the developing world, their lower cost and their wellestablished clinical efficacy [36]. It should be noted that the risk of relapse and the development of a carrier state have been found to be higher among patients treated with ampicillin than those treated with chloramphenicol [37,38].

Briefly, looking at the changing trends of antibiotic susceptibility of $S$. Typhi in addition to the endemicity of typhoid fever in India, it is necessary to perform regular surveys of antibiogram patterns. Although it appears that chloramphenicol, ampicillin and trimethoprim may become the primary antibiotics for the treatment of typhoid fever in some areas of the country, further monitoring of different parts of the country is needed before a definitive statement can be made.

\section{Acknowledgements}

The authors thank the heads of all the laboratories that referred $S$. Typhi strains to the National Salmonella and Escherichia Centre (National Reference Laboratory), Central Research Institute, Kasauli, India. The technical assistance of Mr Jagdish Kumar is also acknowledged. Thanks are due to Mr Jiwa Ram for supplying media and biochemicals for biotyping.

\section{References}

1. Gautam V, Gupta NK, Cahudhary U, Arora DR (2002) Sensitivity Pattern of Salmonella serotypes in Northern India. Brazilian Journal of Infectious Diseases 6: 281-287.

2. Rowe B, Ward LR, Threlfall EJ (1997) Multidrug-resistant Salmonella typhi: A worldwide epidemic. Clin Infect Dis 24: S106-109.
3. Lakshmi V, Ashok R, Susmita J, Shailaja VV (2006) Changing trends in the antibiograms of Salmonella isolates at a tertiary care hospital in Hyderabad. IJMM 24: 45-48.

4. Threfall EJ, Ward LR, Rowe B, Raghupathi S, Chandrasekaran V, Vandepitte J, Lemmens P (1992) Widespread occurrence of multidrug resistant $S$. typhi in India. Eur J Clin Microbiol Infect Dis 11: 990-993.

5. Wang F, Gu XJ, Zhang MF, Tai TY (1989) Treatment of typhoid fever with ofloxacin. J Antimicrob Chemother 23: 785-788.

6. Asperilla MO, Smego RA, Scott LK (1990) Quinolone antibiotics in the treatment of Salmonella infections. Rev Infect Dis 12: 873.

7. Maheshwari VD and Agarwal SK (1996) Present status of drug resistance in cases of enteric fever in Rajasthan. $\mathbf{J}$ Assoc Physicians India 44: 618-619.

8. Misra RN, Bawa KS, Magu SK, Bhandari S, Nagendra A, Menon PK. (2005) Outbreak of multidrug resistant Salmonella typhi enteric fever in Mumbai garrison. Medical Journal Armed Forces India 61: 148-150.

9. Krishnan P, Stalin M, Balasubramanian S (2009) Changing trend in antimicrobial resistance of Salmonella enterica serovar Typhi and Salmonella enterica serovar Paratyphi A in Chennai. IJPM 52 : 505-508

10. Ray P, Sharma J, Marak RS, Garg RK (2006) Predictive efficacy of nalidixic acid resistance as a marker of fluoroquinolones resistance in Salmonella enterica var Typhi. Ind J Med Res 124: 105-108.

11. Gupta V, Kaur J, Kaistha N (2009) Re-emerging chloramphenicol sensitivity and emerging low level ciprofloxacin resistance among Salmonella enterica serotype Typhi isolates in North India. Trop Doct 39: 28-30.

12. Crump JA, Kretsinger K, Gay K, Hoekstra RM, Vugia DJ, Hurd S, Segler SD, Megginson M, Luedeman LJ, Shiferaw B, Hanna SS, Joyce KW, Mintz ED, Angulo FJ, the emerging infections program and foodnet and NARMS working group (2008) Clinical response and outcome of infection with Salmonella enterica serotype Typhi with decreased susceptibility to fluoroquinolones: a United States foodnet multicentre retrospective cohorot study. Antimicrob Agent Chemother 52: 1278-1284

13. Lesser CF and Miller SI (2001) Enteric (Typhoid) fever. In: Braunwald E, Fauci AS, Kasper DL, Hauser SL, editors. Harrison's Principles of Internal Medicine. $15^{\text {th }}$ ed. New York: McGraw-Hill Companies Inc, 971-972.

14. Nagshetty K, Channappa ST, Gaddad SM (2010) Antimicrobial susceptibility of Salmonella Typhi in India. J Infect Dev Ctries 4: 070-073.

15. Manchanda V, Bhalla P, Sethi M, Sharma VK (2006) Treatment of enteric fever in children on the basis of current trends of antimicrobial susceptibility of Salmonella enterica serovar Typhi and Paratyphi A. IJMM 24 : 101-106.

16. Raveendran R, Wattal C, Sharma A, Oberoi JK, Prasad KJ, Datta S (2008) High level ciprofloxacin resistance in Salmonella enterica isolated from blood. IJMM 26: 50-53.

17. Dutta S, Sur D, Manna B, Bhattacharya SK, Deen JL, Clemens JD (2005) Rollback of Salmonella enterica serotype Typhi resistance to chloramphenicol and other antimicrobials in Kolkata India. Antimicrobial agents and chemotherapy 49: 1662-1663.

18. Sen B, Dutta S, Sur D, Manna B, Deb AK, Bhattacharya SK, Niyogi SK (2007) Phage typing, biotyping and 
antimicrobial resistance profile of Salmonella enterica serovar Typhi from Kolkata. IJMR 125: 685-688.

19. Achla P, Grover SS, Bhatia R, Khare S (2005) Sensitivity index of antimicrobial agents as a simple solution for multidrug resistance in Salmonella Typhi. IJMR 121: 185193.

20. Chande C, Shrikhande S, Kapale S, Aggarwal S, Fule RP (2002) Changes in antimicrobial resistance patterns of Salmonella Typhi in Central India. IJMR 115: 248-250.

21. Mandal S, Mandal MD, Pal NK (2004) Reduced minimum inhibitory concentrations of chloramphenicol for Salmonella enterica serovar Typhi. Indian J Med Sci. 58: 16-23.

22. William RH (1994) Group 5: Facultatively anaerobic Gram negative rods. In Bergey's manual of determinative bacteriology. $9^{\text {th }} 270$ ed Baltimore: Williams and Wilkins 175-201.

23. Popoff MY and Le Minor L (1992) Antigenic formulas of the Salmonella serovars. 7th revision. WHO Collaborating Centre for Reference 264 Research on Salmonella. Paris: Institut Pasteur.

24. National Committee for Clinical Laboratory Standards: Performance Standards for antimicrobial disc susceptibility tests, 7th ed. Approved standards M2-A6. Wayne Pa: National Committee for Clinical Laboratory Standards, 2000.

25. Clinical and Laboratory Standards Institution: Methods for Dilution Antimicrobial Susceptibility Tests for Bacteria that Grow Aerobically. Approved standard, CLSI document M7A7. Wayne, PA: Clinical and Laboratory Standards Institute, 2006.

26. Madhulika U, Harish BN, Parija SC (2003) Current pattern in antimicrobial susceptibility of Salmonella Typhi isolates in Pondicherry. Indian J Med Res 120: 111-114.

27. Bhatia JK, Mathur AD, Arora MM (2007) Reemergence of Chloramphenicol Sensitivity in Enteric Fever. MJAFI 63: 212-214.

28. Tankhiwale SS, Agrawal G, Jalgaonkar SV.(2003) A preliminary report on current antibiogram of Salmonella enterica serotype Typhi in Nagpur. IJMM. 21(4) : 292

29. Misra RN, Bawa KS, Magu SK, Bhandari S, Nagendra A, Menon PK (2005) Outbreak of multidrug resistant
Salmonella Typhi enteric fever in Mumbai garrison. MJAFI 61: 148-150.

30. Karmakar S, Biswas D, Shaikh NM, Chatterjee SK, Kataria VK, Kumar R (1991) Role of large plasmid of Salmonella typhi encoding multiple drug resistance. Journal of Medical Microbiology 34: 149-151.

31. Jesudason MV, John R, John TJ (1996) The concurrent prevalence of chloramphenicol-sensitive and multidrugresistant Salmonella typhi. in Vellore, S. India. Epidemiol Infect 116: 225-227.

32. Pitlik S (2003) Old drugs for new bugs. BMJ 326: 235-236.

33. Renuka K, Sood S, Das BK and Kapil A (2005) High-level ciprofloxacin resistance in Salmonella enterica serotype Typhi in India. J Med Micro 54: 999-1000.

34. Mehta G, Randhawa VS, Mohapatra NP (2001) Intermediate susceptibility to ciprofloxacin in Salmonella typhi strains in India. Eur J Clin Microbiol Infect Dis 20: 760-761.

35. Kapil A and Das B (2002) Nalidixic acid susceptibility to screen ciprofloxacin resistance in Salmonella Typhi. Indian J Med Res 115: 49-54.

36. Kumar Y, Sharma A, Mani KR (2009) High Level of Resistance to nalidixic acid in Salmonella enterica serovar Typhi in Central India. J Infect Dev Ctries 3:467-469.

37. Sood S, Kapil A, Das B, Jain Y, Kabra SK (1999) Reemergence of chloramphenicol-sensitive Salmonella typhi. Lancet 353: 1241-1242.

38. Yew FS, Chew SK, Goh KT, Monteiro EHA, Lim YS (1991) Typhoid fever in Singapore: a review of 370 cases. Journal of Tropical Medicine and Hygiene 94: 352-357.

\section{Corresponding author}

Yashwant Kumar

National Salmonella and Escherichia Centre

Central Research Institute

Kasauli (HP) - 173204

India

Telephone: +91-1792-272059 Ext. 218

Email: yasht26@yahoo.co.in

Conflict of interests: No conflict of interests is declared. 